\title{
Study groups and peer roles in mediated academic literacy events in multilingual educational contexts in South Africa
}

\section{Felix Banda}

Department of Linguistics, University of the Western Cape, Private X17 Bellville, 7535

Email: fbanda@uwc.ac.za

\section{Introduction}

This paper explores the role of study groups in mediating academic writing, particularly among multilingual black students at the University of the Western Cape (UWC). Using data from questionnaires, focus groups, and interviews, as well as academic texts generated by study groups, the paper focuses on the efficacy of study groups in mediating literacy events in multilingual educational contexts. Of particular interest here is the composition, i.e. the roles each member plays in the preparation and discussion of a particular topic.

Considering that the language used in study group discussions is often not that used as the medium of instruction, or that in which students usually do their academic writing, the pedagogical implications of assigning roles in study groups are discussed in relation to effective facilitation of peer learning in multilingual contexts.

Until the 1980s, the University of the Western Cape was a so-called "coloured" university, in that it had been established under apartheid in the 1960s to cater for those classified as mixed race, who were largely Afrikaans L1 speakers. However, in the recent past the number of black students entering UWC has swelled. Most of these are Xhosa L1 speakers. A number of 


\section{Felix Banda}

these students come either from the rural areas of the Eastern Cape, or from the sprawling townships of the Cape Flats, where poverty and gangs prevail.

\section{English second language writing in multilingual contexts}

That black students often have difficulties with English second language (ESL) academic writing is well documented (cf. Alexander 2005; Banda 2003, 2004; Gough and Bock 2001). This problem is not unique to South Africa, and it has not deterred positive attitudes towards English. This also appears to be the case elsewhere in Africa (see Brock-Utne, Desai, and Qoro 2003, 2005; Alexander 2005; Banda and Kirunda 2005). In South Africa, research has shown overwhelming support among black learners and parents for either English-only or English-mother tongue bilingual programmes (De Klerk 1996, 2000; Banda 2000, 2003, 2004), preferably from grade 1 . However, this perspective has been disabused by academics and policy makers, who have counter-argued that "education in the mother tongue is always everywhere the only correct and most natural procedure" (Kishindo 1999: 34). Mostly owing to socio-economic reasons and the status attached to English, black parents are unconvinced about monolingual mother tongue education, which they deem inferior, and those who can send their children to former white or coloured schools do so (Banda 2004). In essence, there is a disjuncture between parental and learner aspirations and expectations regarding classroom practice, on the one hand, and actual classroom practice and language in education policy on the other. Nowhere is the consequence of the mismatch felt more than in township and rural schools and homes. I wish to argue that parents' practice of transferring their children from township or rural schools to former white schools is in part a reflection of failed education policy, which does not consider parental and learner aspirations to at least a bilingual education, in which both the mother tongue and English are used as languages of learning and teaching (LOLT) of content matter subjects. It is also a reflection of unequal language planning and policy which rewards those who successfully indulge in English. Thus, policy and practice force parents to uproot their children from their communities and move them to other areas in search of a better education and the associated socio-economic mobility.

However, even without considering strong attitudes and status issues, as Banda (2004) has argued, from an African parent's perspective the choice is not always between ESL and an African language. Although both could have a role to play in a bilingual education set-up, 
parents and learners find that in education they mostly engage with written texts in English, rather than in their mother tongue. Unlike Afrikaans learners, those from Xhosa and other African languages do not engage with written texts in their first language, and cannot write in their mother tongues even if they wanted to. The main reason for this is that government examinations for grade 10 learners in black communities are set in English (with the exception of the language subjects), and the majority of teachers at both secondary and tertiary levels have not been trained to teach in African languages. Additionally, despite proclamations of 11 official languages, there is still a dearth of teaching and reference material in all languages except English, and African language departments at universities that would be harbingers of a better dispensation in the near future, have virtually no students (Webb and Kembo-Sure 2000).

In the meantime, students from African language speaking homes will continue to be disadvantaged and thus will continue to seek strategies to mediate their ESL academic writing problems. Strategies used by Xhosa L1 speaking students with varying degrees of success include translation and code-switching (Banda 2003). The present paper focuses on the manner in which Xhosa students use study groups to mediate academic writing in ESL. My interest is in the kind and quality of discussions that take place among peers in a study group, arising out of the different roles they play in the peer group discussions. Roles in a study group may, for example, range from who collects what information and where, to different functions each member plays in the group, such as chairing and directing the discussion.

\section{Theoretical and methodological issues}

In recent years, a number of studies have focused on literacy mediation. In the area of New Literacy Studies, the notion of 'literacy mediator' has been used in a largely sociological and sociolinguistic sense, for example with regard to social networks (Barton and Ivanic 1991); teenagers as mediators in black and Puerto Rican communities (Shuman 1993); mediation as a strategy for achieving literacy purposes in the Moroccan community in London (Baynham 1993, 1995); mode and discursive switching (Malan 1996); and translation and codeswitching as academic literacy mediation (Banda 2003). In all these studies, mediation is a consequence of difference and distance. Difference and distance refer to mediation as having to do with closing an information gap, both in terms of knowledge and socio-psychological 
factors (Baynham and Masing 2000: 195). The present paper focuses on the composition of the study groups involved, particularly on peer roles in study groups in multilingual contexts, where the language used for discussion is not necessarily the language of academic writing.

\section{The study}

The data on which this study is based was originally collected in a survey of literacy practices among black and coloured students at UWC. A total of 120 black and coloured students from year 1 to year 3 took part in the initial survey. The survey was part of a larger study on multilingualism, multiliteracies, and access to various domains as derived from the Constitution of the Republic of South Africa (Act 108), with provisions to inclusive citizenship through equality of political processes, language, education, employment and freedom of expression (Government of South Africa 1996). Among other issues, the survey compared the reading and writing habits (including the kinds of TV programmes watched) between urban and rural students, coloured and African students, as well as the availability of reading materials and resources (e.g., libraries) and their management at home and at school.

The survey part of the present study focused on 85 black students. My focus in the survey data is on information on the students' LOLT during primary and secondary school and higher education, and on the kinds of literacy mediation received.

The present study also involved follow up interviews with 10 selected students on the basis that in the initial survey they had indicated their willingness to be interviewed with regard to their literacy practices. Based on their responses to the interviews, and on whether they participated in a study group, permission was sought from 5 students and their group members to have one of their discussion sessions recorded. In other words, the 5 focus groups were based on already existing study groups. For the present study, data from only two focus groups were used. The first criterion for the selection of the two groups was that they were discussing a similar topic. Secondly, the one group (study group 1) conducted their discussion almost exclusively in Xhosa, and also happened to have one member who had failed the second year communication studies course for 3 years running, and was known by the researcher to have serious ESL academic writing problems. The other group (study group 2) conducted discussions exclusively in English, and one of the students in the group was known 
by the researcher to have good writing skills and passed his communication studies course in the first semester with more than $70 \%$. All the participants reported that Xhosa was their L1. Both the interviews and study group sessions were recorded on audio tape.

\section{Findings and discussion}

\subsection{Language of learning and teaching}

Xhosa and a mixture of Xhosa and English constitute the main LOLTs of primary education; $40 \%$ of the respondents in the study claimed Xhosa as the sole LOLT, and $47 \%$ claimed Xhosa/English as LOLT. Only one respondent said s/he had English as sole LOLT. Effectively, almost 50\% came from schools where teachers used their initiative, contrary to language policy, to teach using two languages at primary school.

At secondary school level, the percentage for mother tongue only as LOLT dropped to 6\%, while for Xhosa/English bilingual learning and teaching, it increased to 63\%. It is worth noting that only $17 \%$ of respondents claimed they received their education in English only.

The problem here is that the language in education policy does not encourage writing in ESL at lower primary level (grades 1-4), whereas learners are expected to do their writing in English from grade 5 onwards, even though teaching and oral classroom interaction are in either Xhosa or Xhosa/English combined. This results in learners being shunted from mother tongue-based monolingual education to English-based monolingual education.

\subsection{Literacy mediation}

The first observation one can make regarding parent involvement debunks the myth that African parents, in particular those in rural areas, do not help with their children's homework. Indeed, parents do play a mediating role in their children's education. This is also in line with Gough and Bock's (2001) finding that black parents indeed help their children with their reading and writing. In this study, $60 \%$ of the respondents said that they received assistance from their parents or guardians most of the time, as compared to only $10 \%$ for the study groups. It is not certain what kinds of mediation roles parents play where they can neither read nor write. This aspect requires further research. 
However, at secondary school level, the role of parents as mediators diminishes as the role of study groups increases. At this stage, reportedly $20 \%$ received assistance from parents or guardians most of the time, compared to $60 \%$ who received assistance from study groups.

At university level, the use of tutors $(80 \%)$ and study groups (67\%) as mediators appears to be critical. Since tutors are chosen from amongst current and former students who show an aptitude for academic work, it is not surprising that students find their assistance as mediators useful. For students in the group under study, tutors themselves had Xhosa as home language. However, a shared Xhosa/English repertoire did not translate into a multilingual approach from the tutors. During the interviews it became evident that tutors did not use Xhosa in tutorials, or during consultation in their offices. Like lecturers, they used English only, thereby not effectively utilising their multilingual competence. One explanation for this is that tutors have been taught, in particular at university, to operate academically in English only. Another explanation could be that current language policy and planning is such that it makes learners and teachers alike believe that academic exercises are the preserve of English. A final reason may be that they use English as a marker of status to show that they are academically superior.

As will become evident in what follows, these explanations can also be used to validate the odd situation in which students discuss their academic work in Xhosa, but opt to do their writing in English, and in fact refuse to write academic texts in Xhosa.

\subsection{Follow up interviews}

As mentioned above, in order to gather information about the efficacy of study groups, 10 follow up interviews were conducted, and 5 study groups recorded in action. The extracts of only two contrasting groups are considered here: one which I consider to be unsuccessful and the other successful in terms of role structuring in the study group, for effective group discussion of the topic in preparation for ESL academic writing.

Banda (2004) argues that students often find the translation of material between the discussion of a topic in a study group, which is usually in Xhosa, and writing it in academic ESL, rather frustrating and often unproductive. As is suggested by Extract 1, students sometimes do not understand the supplementary readings that are supposed to help them in discussing particular 
topics; thus they use the study group as a tool to mediate in their academic writing. Reference material is exclusively in English, and it is a matter of conjecture as to whether translated material in Xhosa (were it available) would make a positive contribution to the problem of academic writing.

\section{Extract 1}

Interviewer: What about the books and the coursework material, and the books in the library, do you find them easy to understand?

Thembe: $\quad$ They are too complicated.

Interviewer: Which ones?

Thembe: The books in library because the authors are saying things that are not relevant to other authors.

Interviewer: Did you do a lot of reading in English before you came to the University?

Thembe: No. Like me I grew up in rural area where everything was taught in Xhosa even if is English.

The extract demonstrates that even where the material is available in ESL, some students find it difficult to understand how the various sources relate to each other. For many students, understanding the language of academia is difficult enough in the first language. It is furthermore most probably extremely difficult for students who were poorly taught at primary and secondary school in ESL. The argument here is that no meaningful group discussion can take place if the students find the sources of knowledge impenetrable. Thembe, like others in her situation, tended to blame the mother tongue and her acculturation into it for her lack of academic writing proficiency in ESL. I wish to argue that the real problem lies in a language policy that recognises one language as the main vehicle for education, a policy that legitimises monolingual education by proclaiming that education in the first 4 years should be in the mother tongue, and thereafter in English. Apart from poor teaching through the ESL which leaves students ill-prepared for higher education academic writing (cf. Banda 2003, 2004), the current language in education policy primes learners and parents to abandon their mother tongues after initial literacy development.

In short, Extract 1 shows that the root of the difficulties with academic ESL may sometimes be traced to a point before students enter university, and before the study groups meet to 
discuss a particular topic or task. In essence, students have not been adequately schooled, and thus fail to utilise their multilingual repertoire and resources that could otherwise prove beneficial to their academic writing tasks.

It became clear from the interviews that students had mixed feelings about the effectiveness of study groups in helping them with their academic work. What also became evident was the danger of staying in an unproductive study group. Clearly, participants in Vuyo's study group (cf. Extract 2) feel that they have to meet, hoping something will happen even when they know that they "don't have answers".

\section{Extract 2}

Interviewer: So do study groups, in which you discuss in Xhosa, help you pass or understand your work better?

Vuyo: $\quad$ Sometimes they help me pass but it's nothing for sure. We usually tackle a subject we don't know until we can at least be fine with it. We just do it so we can pass.

Interviewer: So you have doubts about whether they help you pass. You're sure though that they help you understand the work better?

Vuyo: $\quad$ Sometimes, we can work as a group, but we don't understand the question but we keep telling ourselves that we are going to answer the question although we don't have enough answers. That probably is the reason we are not sure whether they help us pass.

Extract 2 illustrates the importance of lecturers being aware of the existence and practices of study groups and their potential to aid or to hinder academic learning. Unregulated study groups could be counter-productive, without members being aware of this. In this regard, students may feel duty bound to attend peer study events when they may have been better off studying on their own, or consulting a tutor or lecturer, or indeed looking for information in supplementary readings. However, even if we were to take the view that Vuyo's study group was unproductive, it still enables members to interact and to engage with texts that may otherwise remain opaque in ESL verbiage. Furthermore, both psychologically and pedagogically, peer learning enables students such as Vuyo to become part of the learningteaching process, albeit outside classroom walls. This opportunity they would otherwise 
forfeit, owing to ESL barriers. It is in this light that Vuyo's despair and attempt at stoicism should be regarded, as in "We usually tackle a subject we don't know until we can at least be fine with it. We just do it so we can pass."

From Extract 3 below, it is clear that one of the problems students find with peer study groups is that, when it comes to exams, they feel lost and lonely. The confidence that one may have gained by solving problems in a study group vanishes, giving way to feelings of vulnerability.

\section{Extract 3}

Interviewer: What about the study groups like even now before the exams how helpful do you find them. Do they help with understanding the academic work and passing the exams?

Tombi: $\quad$ The study groups are helping but the problems when you go to exam room you are alone so they pass or fail.

Velo: $\quad$ That is the problem. And most of them they don't come up with information they have they want you to say what you know.

Even though study groups could potentially help in academic mediation, the size of the group and the expertise of members are also matters of importance. The latter is particularly important as it enables peers to assume different roles in the group. However, a large study group could be counter-productive as a result of role duplication, which could possibly lead to conflict and antagonism among members. Research has shown that study groups could turn out to be a source of conflict, where it is felt that not all members are getting equal benefit from the group (cf. Gocsik 2005). In this regard, consider Zuki's and Nandi's experiences related in Extract 4.

\section{Extract 4}

Interviewer: You study with 3 other students.

Zuki: $\quad$ Yes but last year we were more than 8 but we found out that we are just playing then we decided to split the group into two, then I chose to be in this one because they are serious they don't play when we are doing our work.

Interviewer: Okay, you were 8 and nothing was happening and people were just playing around. 
Zuki: $\quad$ Yes they were just playing.

Interviewer: And what happened to the other group members, are they still here?

Zuki: $\quad$ Yes.

Interviewer: And how was the performance in the group, were they helping with academic work? What was happening?

Zuki In the second group?

Interviewer: No, the old group.

Zuki: $\quad$ The old group it was only me and Nandi who were always passing and when the results come there was a negative attitude on us because we are passing and they are failing.

Interviewer: So what you are saying is that study group didn't help everybody.

Zuki: $\quad$ Yah, it doesn't help everybody.

Interviewer: But in general now that you are in this group does it help?

Zuki: $\quad$ Yes I can say it helps, but ...

Interviewer: Oh! You, you are not sure?

Zuki: $\quad$ Yah I will say it is helping me. [Not Nandi]

Interviewer: Which one? Understanding or passing the course?

Zuki: $\quad$ To understand ... because I work for myself to pass.

Considering the reported difficulties students experience with academic English, one would expect them to embrace the use of Xhosa if available. This is particularly so since study group discussion usually takes place in Xhosa or in a mixture of Xhosa and English. As Extract 5 below illustrates, this is not necessarily the case. Furthermore, as has been alluded to before, students have been socialised to believe that the only good education is one in English. In particular, academic writing is thought to be the preserve of English. For Zethu and other students, there is no place for Xhosa in higher education, particularly not in academic writing.

\section{Extract 5}

Interviewer: So you wouldn't mind if that question was in Xhosa and you have to answer that question in English.

Zethu: $\quad$ Yah it won't cause problem because I can think more in Xhosa. My problem in English you think but you can't find the good word then you end up leaving the information because it will be poor, it can't make sense. 
Interviewer: What if we start we start teaching at University in Xhosa?

Zethu: Nooo! [emphatically]

Interviewer: Why not, but that will be easier won't it?

Zethu: $\quad$ Yah, what? But all subjects in Xhosa? Some of them must be in English I don't agree with that.

Interviewer: Why in English?

Zethu: $\quad$ I think it will be boring learning Xhosa all the classes.

\subsection{Analysing study group discourse}

As mentioned above, to get an indication of what happens during study group discussions, some groups were recorded in action. Extracts from two study groups are presented and discussed below.

\subsubsection{Study group 1}

Extract 6, from study group 1, illustrates what should not happen in peer learning. The participants appear to be aware of what is required with regard to the topic. However, the way they go about discussing it makes it difficult for them to engage with the topic constructively and critically, let alone meaningfully. This prevents them from being able to take each other's perspectives, or even to take an opposing view, as is often the case in academic discussion of this nature.

\section{Extract 6}

[The group is in the library basement discussing gender roles and HIV/AIDS in preparation for the $3^{\text {rd }}$ year final examination the next day in a course on Women and Gender Studies. All three participants are female. The transcription symbols used here are those of Eggins and Slade (1997), given in Table 1 below the extract.]

Zuki: Abonabantu banezifo more than bona ngabafazi, nangona ingabo abantu abalala nabafazi abaninzi. Then amadoda awafuni kuyazi into yokuba aids ikhona and abafazi abanazipowers zokuthi masisebenzise icondom $==$ Most people who have the disease are women compared to men, although it is them who sleep around. Then men don't want to know the fact that AIDS is there, and women do not have power to say no we should to use a condom = = 
Nandi: $\quad=$ ngoba indoda mhlawumbi izakucinga ukuba ikho into ayenzayo umfaziecaleni, and number two

$==$ because may be men think that you sleep around and number two (secondly)

Zuki: Abakwazi kuthetha ngeecondoms emadodeni abo because baxhomekeke kuwo like in terms of ishelter, ukutya nezinye izinto. So bonqena ukungazifumani ezozinto.

And they don't speak freely about condoms and sexual related topics to their husbands because they depend on them in terms of food shelter and etc. So they are forced to accept any thing from their men.

Nike: Amasiko or iculture nayo inegalelo kulento yokwanda kwe AIDS ngoba iculture ye africans kwirural areas abakho allowed to discuss I sex naba yeni or amadoda abo, xa ungumntu ongumama you have to tell your child about sexual deases $=$

Culture also has an effect on the spread of HIV and AIDS, because the African culture in rural areas doesn't allow women to talk about sex to their husbands, so if you are a woman it is your responsibility to see it to it that you tell your child about sexual disease $=$

Zuki: $\quad==$ and like ukuba uyafumanisa kwezindawo kuthethwa kuzonge AIDS amadoda awekhongabafazi bodwa $==$

and like if you can go around in the places where there are discussions about AIDS men don't attend

Nandi: and amadoda ayasoleka kulento yokwanda kweaids, indoda isuka kwi rural areas to urban areas eyokufuna umsebenzi then phayana afune umntu wokuthatha indawo nemisebenzi yomfaziand benze isex ngaphandle kokhuseleko, abuyengeholide aze emfazini nezoo zifo and men are always to blame for spreading AIDS, because men move from rural areas to urban areas in search of work and when they get there they engage themselves in relationships and they have unprotected sex and during the holidays they will go back to their wives with those diseases

Nike: and norhulumente sisenokumsola kulento like kwi public institutions kufumaneka imakle condoms zodwa so kubafazi kunzima ukuzikhusela baxhomekeke emadodeni abo 
and also we can blame government about the spread of AIDS because in public institutions it is only male condoms that are mostly available, no female condoms, and that makes it difficult for women to ensure that they are safe. They have to depend on their partners.

Nandi: $\quad$ Yintoni umahluko phakathi kwegender streotypes ne gender role?

What is the difference between gender stereotypes and gender role?

Zuki: $\quad$ Mna igender role ndiyibona iyintoelungelelaniswa yi culture, like umfazi kumele apheke indoda kumele isebenze izinto ezinjalo. Then igender stereotypes yona, abantwana bafunda ebantwini abadala indlela yokuphila, like xa uyintombazana udlala onopopi inkwenkwe igani neemoto njengotata bawo In my opinion gender role is the way culture shapes the way of living, such as, women cook and men work. Then gender stereotypes, children learn the way of living and to behave from their elders. That is if you are a girl you learn what your mother is doing, you play with dolls, pretend to have babies and boys from their fathers playing with guns and etc

Nike: and iculture esiphila kuyo ikhuthaza into yokuba amadoda akwazi ukuziphilela angaxhomekeki mntwini.

and our culture also motivates or encourages the fact that men should be independent

Nandi: $\quad$ Okunye amadoda acinga ukuba abhetele kunabafazi

Also men think that they are better than women

Zuki: Kwingxoxo yethhu yokuqala besifuna ukuqonda ukuba kutheni lento iAIDS iyigender issue, kweyesibini besiqonda umahluko phakathi kwe ender role ne stereotypes.

In our first discussion we wanted to know why AIDS is regarded as a gender issue. In our second discussion we wanted to know the difference between gender role and gender stereotypes.

(Banda 2003: 80-81) 


\begin{tabular}{|c|l|}
\hline$\cdot$ & Certainty, completion (typically falling tone) \\
\hline No end of turn & Non - termination (no final intonation) \\
\hline, & Parceling talk; breathing time \\
\hline$?$ & Uncertainty (wh-interrogative) \\
\hline$!$ & 'surprised' intonation \\
\hline() & Untranscribable talk \\
\hline (words within parenthesis) & Transcriber's guess \\
\hline [Words in square brackets] & Non-verbal information \\
\hline$==$ & Overlap (contiguity, simultaneous) \\
\hline
\end{tabular}

Table 1. Transcription conventions (Eggins and Slade 1997)

As Banda (2003) notes, the text reads like a rehearsed essay being restated in a mixture of Xhosa and a sprinkling of English. Such "Xhosalisation"1 ${ }^{1}$ of the texts, in which English labels have been replaced with Xhosa, does not demonstrate real understanding (Banda 2003). In terms of knowledge transfer between languages, translation of texts needs to involve translation of cognitive concepts and structures from ESL to cognitive concepts and structures in Xhosa and vice versa. This would mean active commenting, reshaping and transformation of L1 and L2 knowledge into new knowledge. However, what is happening here may be termed "scribing", i.e. "faithful transmission of a message without any intervening shaping on the part of the messenger" (Baynham and Masing 2000: 192, my emphasis). As a result, the discussion does not lead to the development of new knowledge and new texts, as the students take the role of scribers. Note, in this regard, the overuse of because. The use of because indicates that the students are able to avoid discussing the "how", which would demand justification for the particular line of argument, and hence a more in-depth exposition of the topic. Because the students offer no support for their reasoning, the text reads like a stereotypical and generalised portrayal of African men and culture. This is the very approach against which the course aims to teach them to guard. Note also the futility of Zuki's attempt at summarising what has been discussed (in her final turn), which ends up being a restatement of the subject of discussion, rather than a restatement of interpreted, transformed and reshaped text.

A study group will only be effective if its members have specific tasks to perform. For example, members may be directed to different sources of information or focus on different aspects of a topic, and then present their material to the group. The main problem with study group 1 is that it is not clear what role each one is expected to play. It appears that they are all 
contributing from the same relatively insufficient source of information, and there is no clear facilitator. Moreover, there is no attempt at a critical appraisal of the source or at extending knowledge. Additionally, unlike the case of study group 2 below, there is no deliberate attempt to contextualise the topic in South Africa's socio-cultural context to arrive at a deeper understanding of the subject.

\subsubsection{Study group 2}

Extract 7 below is from a group of $2^{\text {nd }}$ year students discussing boundaries of counselling relationships. There are five participants involved, two male and three female.

\section{Extract 7}

Veli: Changing boundaries of the counselling relationship, right

Sam: $\quad$ Ya!

Veli: It's whereby working with an HIV positive client may force the counsellor to alter the traditional parameters of the relationship e.g., seating, time frame for a session, duration of the relationship, payment schedule and insurance policies. The counsellor has to change the boundaries. You remember there are boundaries in counselling that we were talking about in Chapter 14.

Zama: $\quad$ Mmh

Veli: Then, when in this counselling the ethics should be changed? They no longer need to be applied. He is not working with a normal client. This client is HIV positive. The way of seating and time frame should be arranged. You'd find that the client coughs $==$ because of the HIV status.

Musa: $\quad==$ you have to expand or limit the time.

Veli: Do you understand me? Also you must ask the client if they have joined any insurance policies, you see. Because there is now "living towards death". When do you pay me? $==$ because once you die there'll be a problem. I don't know where I'll get my money

Musa: $\quad==$ because you'll die next week! [laughter]

Veli: $\quad$ Come again

Busi: the payment schedule

Veli: no, it's just an example, example of this one 
Sam: the client has overcome the boundaries that "I cannot speak, talk openly and do this and that" $==$

Busi: $\quad==$ it's like he's not like someone who has a certain problem. This problem is worse than others. This one has HIV, it's not like where you had a conflict with your wife, then explain what happens exactly. This one $==$

Musa: $\quad==$ that's why the situation changes, because the process ( )

The difference between Extracts 6 and 7 is all too apparent. Unlike study group 1, the members of group 2 engaged not only with the topic, but also with each other. It is also clear that they are using each other's prior knowledge as building blocks towards transforming and reconstructing knowledge to achieve a better understanding of the topic. The role Veli is playing in group 2, whether by design or default, is critical here. He initiates the discussion (turn 1), directs the discussion, reminds the group of the topic, and points them to important sources of information outside the vicinity of the group (turn 3). He cajoles information from the group and seeks confirmation (turn 5). He also makes certain that everybody understands the topic of discussion (turn 7). I will argue that, rather than dominating the discussion, he is playing the role of a facilitator, while the rest of the group act as information sources. Not only that, the group members also throw in jokes, thus effectively utilising their own sociocultural experiences to reformulate and deconstruct what they are familiar with regarding HIV/AIDS.

The choice of appropriate words and phrases, including word-play such as living towards death (turn 7), not only foregrounds the topic, but also shows familiarity with academic language, in addition to contextualising the problem at hand, and placing the discussion of HIV/AIDS in South Africa's social contexts. That the discussion is entirely in English does not render it incoherent, as appears to be the case with some of the interview data discussed above. It is clear that the group deliberately chooses words and phrases of the kinds they are expected to utilise in an academic essay. It is in this light that specialist words and phrases such as traditional parameters, payment schedules, time frame, overcoming the boundaries, conflict, etc. should be seen.

In short, it can be argued that study group 2 not only comes up with a more powerful discursive representation of the topic at hand, but also shows a better understanding of the 
task at hand than group 1. Through humour and clever contextualisation of HIV/AIDS, for example, and by tapping into the concept of 'living with AIDS' (here referred to as "living towards death") and into experience with black market money lenders who are out to get back their money with interest, they are able to link experiential knowledge of social context to the question. This also enables them to draw on the social context to justify arguments about changing ethics as a result of HIV/AIDS, by which counsellors demand prior payment and insurance from clients before counselling. That people do not always disclose their HIV status poses a major problem for the counsellors, as they are unable to change the parameters of counselling for those who are already infected with the disease, for speedy and effective therapy.

\section{Pedagogical implications and conclusions}

Study groups can play a positive mediating role if properly constituted. Tertiary institutions in South Africa may benefit from the recognition of the advantages offered by instructional methods that promote active peer learning. According to Christudason (2000: 1), active peer learning gives students the opportunity to come up with their own questions, discuss issues, explain their viewpoints and engage in cooperative learning by working in teams on problems and projects. In multilingual contexts, there is an added advantage, as peer learning gives students the opportunity to solve problems effectively in other languages, other than the often prescribed and unfamiliar ESL. It is in study groups that students plan and strategise about what and how they are going to write their essays. However, unregulated informal study groups in a second language situation can turn out to be counter-productive. Myles (2002: 9) warns that "[e]rrors abound in peer review classes or computer mediated exchanges where learners read and respond to each other's compositions. ... [I]nterlanguage talk or discourse is often the primary source of input for many learners." In other words, students can easily pick up and so reinforce errors from other members of the group, and thus undermine the lecturer's efforts. Thus, whatever advantage gained by the use of the L1 is lost if the study group is comprised of students not proficient in the language of academic writing, and worse still, unfamiliar with the subject matter at hand.

One way of attending to the composition of study groups is by establishing them in such a manner that students engage in productive negotiation of meaning around a range of topics. 
This would necessarily involve constructing study groups around students with varying ESL proficiency and knowledge of content. This would help to promote constructive interaction, exploration, comment and engagement within the group and with the various texts. Lecturers, then, need to be actively involved in the composition of study groups. In particular, lecturers need to help in the constitution and regulation of peer study groups around students who have oral proficiency and are skilled writers, and who are also familiar with the relevant writing strategies and rhetorical and cultural conventions in ESL.

The question arises as to how this can be done. Christudason (2000: 1) suggests that, in order to realise the benefits of peer learning, lecturers must provide intellectual scaffolding in the form of adequate preparation, cognitive structuring, and role structuring. It is also important that students are prepared, through a pre-selection process, for the discussion of topics about which all students can safely be presumed to have some relevant knowledge. Cognitive structuring entails that the lecturer offers learners a set of questions that direct them towards a particular academic goal, and toward critical thinking. Role structuring entails devising collaborative processes that get all group members to participate productively (Christudason 2000: 1). As seen above, one of the problems with study group 1 was its composition, in which no particular roles were assigned to its members. As a result, they could not engage with each other or with the topic at hand. In fact, it could be argued that neither cognitive structure nor role structure were part of classroom and study group practice for the students in the present study. For example, there is no real scaffolding, as none of the groups work with a prepared set of questions. Although there appears to be some element of role structure in study group 2, this occurs by default rather than by design, as it appears that discussion revolves around Veli, rather than meaningful interaction among all members of the group.

There is no doubt that in a second language situation in particular, study groups are a reality which lecturers ignore at their peril. Lecturers stand to benefit from taking an active role, by using students as apprentices in co-constructing an academic community. Within the everyday lecturing programme, students need to be taught how to engage with their own texts and the texts of others (Grabe and Kaplan 1996). In essence, students need to be taught how to discuss and write about academic issues in an academic fashion (Kern 2000). Some of these skills are evident in the participants of study group 2, but even here there is lack of critical engagement 
with the topic and with the texts generated by group members, as they all seem content to let Veli lead them.

To conclude, in multilingual contexts such as the Xhosa-English one described in this study, study groups should be aimed at the pooling of different sources and perspectives on a given topic, as well as at enabling students to discuss and synthesize different kinds of information in the language in which they are most comfortable. In a multilingual South Africa, where the language of academic writing, reference and content material is not the home language of students, study groups give students the opportunity to use various linguistic resources, rather than English only, to get involved in academic discourse and in their own academic development. Even students who usually remain inactive in classroom interaction on account of linguistic constraints imposed by the inability to discuss issues comfortably in English, may find their own voice in study groups, where they can call upon their linguistic repertoire to positive effect. However, there is no guarantee that the mere use of the L1 would lead to better academic writing, and I would argue that the benefits described above often remain unrealised, as government-regulated exams in primary and secondary schools, as well as teaching and academic writing in higher education, are generally in English.

In short, current classroom and lecture hall practice is biased towards those African students (and English L1 speakers) most proficient in English, leaving the majority of ESL students vulnerable and potentially jeopardising their education in largely unregulated study groups.

\section{Note}

1. This is where English words are morpho-phonologically adapted to the Xhosa phonological and grammatical system. For instance, kwi-public is pronounced [kwi$\mathrm{p}^{\mathrm{h}}$ abliki].

\section{References}

Alexander, N. (ed). 2005. Mother-tongue based bilingual education in Southern Africa. Cape Town: PRAESA.

Banda, F. 2000. The dilemma of the mother tongue: Prospects for bilingual education in South Africa. Language, Culture and Curriculum 13 (1): 51-66. 
Banda, F. 2003. I can't really think in English: Translation as literacy mediation in multilingual/multicultural learning contexts. Per Linguam 19 (2/3): 66-89.

Banda, F. 2004. Literacy practices in black and coloured communities in South Africa: Towards a pedagogy of multiliteracies. In M.J. Muthwii and A.N. Kioko (eds). New language bearings in Africa. Clevedon: Multilingual Matters. pp. 10-33.

Banda, F. and F. Kirunda. 2005. Factors affecting the initial literacy development of urban and rural learners in the Iganga district, Uganda. Per Linguam 21: 1-22.

Barton, D. and R. Ivanic. (eds). 1991. Writing in the community. London: Sage Publications.

Baynham, M. 1993. Code-switching and mode-switching: Community interpreters and mediators of literacy. In B.V. Street (ed). Crosscultural approaches to literacy. Cambridge: Cambridge University Press. pp. 294-314.

Baynham, M. 1995. Literacy practices. London: Longman.

Baynham, M. and H. Masing. 2000. Mediators and mediation in multilingual literacy practices. In M. Martin-Jones and K. Jones (eds). Multilingual literacies. Amsterdam: John Benjamins. pp. 191-207.

Brock-Utne, B., Z. Desai and M. Qoro (eds). 2003. Language of instruction in Tanzania and South Africa. Dar-es-Salaam: E\&D.

Brock-Utne, B., Z. Desai and M. Qoro (eds). 2005. Language of instruction in Tanzania and South Africa. Dar-es-Salaam: KAD Associates.

Christudason, A. 2000. Peer Learning. Centre for Development of Teaching and Learning 4(1). Accessed at http://www.cdtl.nus.edu.sg/link/jan2000/peer1.htm.

De Klerk, V. 1996. Use of and attitudes to English in a multilingual university. English World-Wide 17(1): 111-127.

De Klerk, V. 2000. To be Xhosa or not to be Xhosa: That is the question. Journal of Multilingual and Multicultural Development 21(3): 198-215.

Eggins, S. and D. Slade. 1997. Analysing casual conversation. London: Cassell.

Gocsick, K. 2005. Using peer groups in the first-year writing classroom. www.dartmouth.edu/ writing/materials/faculty/methods/peergroups.shtml.

Gough, D.H. and Z. Bock. 2001. Alternative perspectives on orality, literacy and education: A view from South Africa. Journal of Multilingual and Multicultural Development 22(2): 95-111.

Government of South Africa, 1996. The South African Constitution: Act No. 108. Pretoria: Government Printer. 
Grabe, W. and R.B. Kaplan. 1996. Theory and practice of writing: An applied linguistic perspective. London: Longman.

Kern, R. 2000. Literacy and language teaching. Oxford: Oxford University Press.

Kishindo, P.J. 1999. Implementing language policy decisions in education: Lessons from research. In G.H. Kamwendo, A.D. Mtenje, J.F. Pfaffe, and B. Sandhaas (eds). Towards a national language policy in education. Proceedings of a symposium on language formulation. Centre for Language Studies, Lilongwe, 7-11 March 1999. pp. $28-40$.

Malan, L.1996. Literacy, mediation and social identity in Newton, Eastern Cape. In M. Prinsloo and M. Breier (eds). The social uses of literacy. Amsterdam: John Benjamins. pp. 105-121.

Myles, J. 2002. Second language writing and research: The writing process and error analysis in student texts. TESL-EJ 6(2): 1-20.

Shuman, A. 1993. Collaborative writing: Appropriating power or reproducing authority. In B.V. Street (ed). Cross-cultural approaches to literacy. Cambridge: Cambridge University Press. pp. 247-271.

Webb, V. \& Kembo-Sure (eds). 2000. African voices. Oxford: Oxford University Press 